\title{
HUBUNGAN PENGETAHUAN IBU POSTPARTUM DENGAN SINDROM BABY BLUES PADA HARI 1-7 POSTPARTUM DI KLINIK ROMAULI KEC. MEDAN MARELAN TAHUN 2015
}

\author{
Fitriyani Pulungan \\ Jurusan Kebidanan Poltekkes Kemenkes Medan
}

\begin{abstract}
Abstrak
Melahirkan adalah sebuah karunia terbesar dan momen membahagiakan bagi wanita.Namun ada wanita yang mengalami depresi setelah melahirkan dan hanya sedikit wanita yang mengetahui dan menyadarinya. Sehingga hampir 70 persen ibu mengalami syndrome baby blues setelah melahirkan. Sebagian besar ibu dapat segera pulih dan mencapai kestabilan, namun $13 \%$ diantaranya akan mengalami depresi postpartum. Penelitian ini bertujuan untuk mengetahui gambaran pengetahuan ibu postpartum dan dukungan suami tentang syndrome baby blues. Penelitian ini bersifat deskriptif analitik dengan desain cross sectional.Populasi dalam penelitian ini adalah seluruh ibupostpartum sebanyak 35 orang di Klinik Romauli.Dan seluruhnya dijadikan sampel dengan teknik accidental sampling. Penelitian menggunakan data primer data sekunder dengan analisis bivariat. Hasil penelitian diperoleh pengetahuan ibu postpartum tentang sindrom baby blues mayoritas berpengetahuan kurang sebesar $48,6 \%$. Ibu post partum mayoritas ibu post partum yang tidak mengalmi syndrome baby blues yaitu 19 orang $(54,3 \%)$ dan minoritas yang mengalami syndrome baby blues yaitu 16 orang $(45,7 \%)$. Hasil uji Chi-Square dengan probabilitas $(\mathrm{p}=0,015)<0,05$ artinya ada hubungan yang signifikan antara pengetahuan ibu post partum dengan syndrome baby blues pada hari 1-7 post partum. Diharapkan kepada tenaga kesehatan meningkatkan penyuluhan dan promosi kesehatan khususnya tentang syndrome baby blues baikkepada ibu postpartum maupun kepada keluarga, disamping itu diharapkan petugas kesehatan dapat memberikan hubungan terapeutik pada ibu yang telah melahirkan.
\end{abstract}

Kata Kunci : Sindrom baby blues, pengetahuan, ibu postpartum

\section{PENDAHULUAN}

\section{Latar Belakang}

Melahirkan adalah sebuah karunia terbesar bagi wanita dan momen yang sangat membahagiakan, tapi kadang harus menemui kenyataan bahwa tak semua menganggap seperti itu karena ada juga wanita yang mengalami depresi setelah melahirkan.Banyak orang menganggap kehamilan adalah kodrati yang harus dilalui dan peristiwa alamiah yang wajar bagi wanita tapi bagi wanita yang mengalami hal tersebut dapat menjadi episode yang dramatis dan traumatis yang sangat menentukan kehidupannya di masa datang.Hal tersebut menyebabkan ibu mengalami stres diiringi perasaan sedih dan takut sehingga mempengaruhi emosional dan sensivitas ibu pasca melahirkan (Suherni, 2009).

Kelahiran seorang anak akan menyebabkan timbulnya suatu tantangan mendasar terhadap struktur interaksi keluarga. Bagi seorang ibu, melahirkan bayi adalah suatu peristiwa yang sangat membahagiakan sekaligus juga suatu peristiwa yang berat, penuh tantangan dan kecemasan. Sehingga dapat dipahami bahwa mengapa hampir 70 persen ibu mengalami kesedihan atau syndrome baby blues setelah melahirkan. Sebagian besar ibu dapat segera pulih dan mencapai kestabilan, namun 13\% diantaranya akan mengalami depresi postpartum (Machmudah, 2012)

Post partum blues tidak berhubungan langsung dengan kesehatan ibu dan bayinya maupun komplikasi obstetrik tetapi bagaimanapun faktor-faktor tersebut dapat mempengaruhi perubahan mood ibu. Gejala-gejala tersebut timbul setelah persalinan dan pada umumnya akan menghilang dalam waktu antara beberapa jam sampai beberapa hari setelah persalinan. Namun pada beberapa kasus gejala-gejala tersebut terus bertahan dan baru menghilang setelah beberapa hari, minggu atau bulan bahkan dapat berkembang menjadi keadaan yang lebih berat (Suherni, 2009)

Baby blues syndrome atau sering juga disebut Postpartum Distres Syndrome adalah perasaan sedih dan gundah yang dialami oleh sekitar 50-80\% wanita setelah melahirkan bayinya. Umumnya terjadi dalam 14 hari pertama setelah melahirkan dan cenderung lebih buruk sekitar hari ketiga atau empat setelah persalinan (Chomaria,2013) 
Satu dari lima ibu muda saat baru melahirkan, diperkirakan mengalami sindrom baby blues. Begitu juga halnya dengan pria.Sebuah penelitian terkini menyebut satu dari sepuluh ayah ternyata juga mengalaminya. James Paulson, peneliti dari sekolah kesehatan Virginia Timur, Amerika Serikat seperti dikutip Livesience mengatakan, bahwa sindrom ini berefek kepada ayah dan ibu. Sindrom yang diderita ayah, durasinya sama dengan ibu. Yaitu tiga hingga enam bulan. Selama itu sang ayah memiliki depresi tersendiri yaitu cenderung lebih sensitif dan gampang marah karena emosi. Kelakuan sang ayah akan berpengaruh negatif terhadap si bayi. Penelitian yang dilakukan Paulson bersama koleganya dilakukan terhadap 28.004 koresponden mendapatkan hasil bahwa sekitar $10 \%$ mengaku depresi saat kehadiran bayi dikehidupan mereka.Bahkan $25 \%$ pria terus depresi hingga bayi berusia enam bulan.(Chomaria, 2013).

Postpartum blues sebenarnya sudah dikenal sejak lama. Savage pada tahun 1875 telah menulis referensi di literatur kedokteran mengenai suatu keadaan disforia ringan pasca salin yang disebut sebagai milk fewer karena gejala disforia ringan tersebut muncul bersamaan dengan laktasi (Suherni, 2009).

Dalam penelitian yang dipimpin Jane Morrell dari Universitas Sheffield, Inggris bagian utara melakukan uji coba yang dipublikasikan pada The British Medical Journal (BMJ) mengidentifikasi 701 ibu hamil di Ontario, Kanada, yang diestimasikan berisiko berkembangnya depresi pasca melahirkan. Dengan mendapat dukungan dari sesama ibu, risiko terkena depresi pada 12 minggu setelah melahirkan berkurang (Rein, 2012).

Prevalensi kejadian baby blues syndrome dari berbagai penelitian berbeda di tiap negara, berkisar antara 10-34. Penelitian di Negara barat menunjukkan kejadian lebih tinggi dibandingkan dengan yang pernah dilaporkan dari Asia. Pada penelitian yang dilakukan terhadap 154 wanita pasca persalinan di Malaysia pada tahun 1995 dilaporkan angka kejadian 3,9\% terbanyak dari ras India $(8,9 \%)$, Melayu (3,0\%), dan tidak adanya kasus pada ras Cina. Penelitian di Singapura dilaporkan angka kejadiannya sebesar 1\% (Hasma, 2011)

Di Indonesia perhatian terhadap masalah baby blues masih kurang. Tidak sedikit orang menganggap bahwa baby blues syndrome hanya dialami oleh wanitawanita di luar Indonesia. Wanita Indonesia dianggap tidak mungkin mengalami baby blues syndrome karena masih tingginya sikap kekeluargaan untuk membantu kerabat yang baru melahirkan. Padahal hasil penelitian yang dilakukan di Jakarta oleh dr. Irawati Sp.Kj menunjukkan $25 \%$ dari $580 \mathrm{ibu}$ yang menjadi respondennya mengalami baby blues syndrome (Rein, 2012)

Penelitian pendahuluan yang pernah dilakukan dibagian/KSMF Obstetri dan Ginekologi FKUP/RSHS Bandung, didapatkan angka kejadian sebesar 33,1\% diantara wanita yang melahirkan secara spontan, dan ternyata didapatkan pula bahwa baby blues syndrome tersebut lebih banyak dijumpai pada wanita pekerja dan mereka yang berpendidikan tinggi. Beberapa penelitian yang telah dilakukan di berbagai tempat di Indonesia antara lain : di Jakarta, Yogyakarta, dan Surabaya pada tahun 1998-2001 ternyata angka kejadian mencolok tinggi yakni sebesar 11\%-30\% dibandingkan dengan kejadian di negara lain yang ada di Asia. Dan penelitian lain didapatkan angka baby blues syndrome yang lebih tinggi yaitu 23,4\%-36,7\% (Papayungan, 2005)

Depresi pasca melahirkan bisa menyerang siapa saja tanpa memandang usia, jenis pekerjaan, tingkat sosial ekonomi, jenjang pendidikan. Berarti semua ibu yang baru melahirkan bisa terserang gangguan ini.Depresi ini bisa berlangsung sebentar (singkat), bahkan ada yang hingga bertahun-tahun. Jika ada yang mengalami kasus semacam ini, peran suami dan anggota keluarga lain sangat dibutuhkan. Tindakan lanjutan pun perlu dipertimbangkan yaitu menemui dokter atau psikolog (Chomaria, 2013)

Sementara itu, hasil penelitian yang dilakukan oleh Machmudah (2010), menjelaskan bahwa kemungkinan terjadinya postpartum blues disebabkan oleh beberapa karakteristik yaitu : rentang umur antara 20-35thn yang memiliki persentase lebih tinggi dibanding umur $<20$ thn atau >35thn yaitu (79\%), tingkat pendidikan dimana semakin tinggi tingkat pendidikan seseorang semakin rentan seseorang mengalami stress yang tinggi ( dalam tingkat SMU dan PT ) yaitu 61,25\%, ibu rumah tangga yang tidak bekerja yaitu $62,5 \%$, ibu primipara (65\%), ibu yang tidak mendapat dukungan sosial termasuk dari suami dan keluarga (60\%). Sehingga hasil dalam penelitian sebagian besar responden mengalami postpartum blues yaitu sebanyak 54 orang $(67,5 \%)$.

Berdasarkan survei awal yang dilakukan di Klinik Romauli pada Januari 2015 diperoleh data bahwa dari 10 orang ibu mengalami baby blues syndrome dimana ibu postpartum lebih mementingkan diri sendiri dan rasa sakit yang dialaminya daripada kondisi bayi yang dilahirkan.

\section{Tujuan}

Untuk mengetahui pengetahuan ibu postpartum tentang sindrom baby blues pada hari 1-7 postpartum di Klinik Romauli Kec. Medan Marelan tahun 2015

\section{METODE}

\section{Jenis Penelitian}

Penelitian ini adalah bersifatdeskriptif analitik dengan desain "cross sectional". Desain penelitian ini dipilih karena data diambil secara bersamaan dalam satu waktu, selanjutnya dinilai hubungan antara variabel independen (pengetahuan) dengan variabel dependen (syndrom baby blues). Data dikumpulkan langsung oleh peneliti dengan menggunakan alat angket

\section{Populasi dan Sampel Penelitian}

Populasi dalam penelitian adalah seluruh ibupostpartum hari 1-7 sebanyak 35 orang di Klinik Romauli Kecamatan Medan Marelan Tahun 2015 dan seluruhnya dijadikan sampel. Pengambilan sampel dilakukan secara accidental sampling, mengambil responden atau sampel yang kebetulan ada atau tersedia. 


\section{Analisa Data}

Analisa data bertujuan untuk melihat hubungan anatara dua variabel independen dengan variabel dependen.Pengujian data dilakukan dengan menggunakan uji statistic Chi-Square $(\alpha=0,005)$, dilanjutkan dengan membahas hasil penelitian dengan menggunakan teori dan kepustakaan yang mendukung.

HASIL

Sindrom Baby Blues

Tabel 4.1 Distribusi Syndrome baby blues ibu post partum di Klinik Romauli Kec Medan Marelan Tahun 2015

\begin{tabular}{llll}
\hline No & $\begin{array}{l}\text { Syndrome } \\
\text { baby blues }\end{array}$ & Jumlah & $\begin{array}{l}\text { Persentase } \\
(\%)\end{array}$ \\
\hline 1. & $\begin{array}{l}\text { Tidak } \\
\text { mengalami }\end{array}$ & 19 & 54,3 \\
2. & Mengalami & 16 & 45,7 \\
\hline & Jumlah & $\mathbf{3 5}$ & $\mathbf{1 0 0}$
\end{tabular}

Berdasarkan tabel 4.1 diatas dari 35 responden, mayoritas ibu post partum yang tidak mengalmi syndrome baby blues yaitu 19 orang $(54,3 \%)$ dan minoritas yang mengalami syndrome baby blues yaitu 16 orang $(45,7 \%)$.

Pengetahuan Responden tentang Sindrom Baby Blues Tabel 4.2 Distribusi Frekuensi Pengetahuan Ibu Postpartum tentang Sindrom Baby Blues di Klinik Romauli Kec. Medan Marelan Tahun 2015

\begin{tabular}{ccc}
\hline Pengetahuan & Jumlah & Persentase \\
\hline Baik & 7 & 20 \\
Cukup & 11 & 31,4 \\
Kurang & 17 & 48,6 \\
\hline Jumlah & 35 & 100 \\
\hline
\end{tabular}

Dari tabel 4.2 di atas, dapat dilihat bahwa mayoritas berpengetahuan kurang sebanyak 17 responden $(48,6 \%)$, dan minoritas berpengetahuan baik sebanyak 7 responden $(20 \%)$

\section{Hubungan Pengetahuan Ibu Postpartum dengan Sindrom Baby Blues}

Dari penelitian yang telah dilakukan, diperoleh pengetahuan ibu postpartum dengan karakteristik berdasarkan umur sebagai berikut :

Tabel 4.3 Distribusi Hubungan Pengetahuan Ibu Postpartum dengan Sindrom Baby Blues di Klinik Romauli Kec. Medan Marelan Tahun 2015

\begin{tabular}{ccccccccc}
\hline & \multicolumn{3}{c}{ Syndrome baby blues } & & Df & $\boldsymbol{p}$ \\
\cline { 2 - 6 } Pengetahuan & \multicolumn{2}{c}{ Tidak } & \multicolumn{2}{c}{ mengala } & & & & \\
& mengalami & mi & & Jumlah & & \\
\cline { 2 - 7 } & $\mathrm{N}$ & $\%$ & $\mathrm{~N}$ & $\%$ & $\mathrm{~N}$ & $\%$ & & \\
\hline Baik & 5 & 71 & 2 & 29 & 7 & 100 & 2 & 0,015 \\
Cukup & 2 & 18 & 9 & 82 & 11 & 100 & & \\
Kurang & 12 & 70 & 5 & 30 & 17 & 100 & & \\
\hline
\end{tabular}

Berdasarkan tabel4.3 diatas, dari 7 orang responden yang pengetahuannya baik, mayoritas tidak mengalami syndrome baby blues yaitu 5 orang $(71 \%)$, dan minoritas mengalami syndrome baby blues yaitu 2 orang (29\%). Dari 11 orang responden yang berpengetahuan cukup, mayoritas yang mengalami syndrome baby blues yaitu 9 orang $(82 \%)$, dan minoritas tidak mengalami syndrome baby blues yaitu 2 orang (18\%). Dari 17 orang responden yang berpengetahuan kurang, mayoritas tidak mengalami syndrome baby blues yaitu 12 orang $(70 \%)$ dan minoritas mengalami syndrome baby blues yaitu 5 orang $(30 \%)$

Hasil analisa menggunakan uji Chi-squaredengan $\alpha$ 0,05 dengan $\mathrm{df}=2$ dan $\mathrm{X}^{2}$ tabel adalah 5,991 dan ditetapkan $X^{2}$ hitung adalah 11,15.Dimana $X^{2}$ hitung lebih besar daripada $X^{2}$ tabel $(11,159>5,991)$,dengan $p 0,004$ $(\mathrm{p}<0,05)$, maka Ho ditolak dan Ha diterima, artinya terdapat hubungan yang signifikan antara pengetahuan dengan pemeriksaan pap smear

\section{Pembahasan}

Pengetahuan Responden Tentang Sindrom Baby Blues

Berdasarkan hasil penelitian pada tabel 4.1, terlihat bahwa dari 35 responden mayoritas berpengetahuan kurang tentang sindrom baby blues sebanyak 17 responden $(48,6 \%)$, dan minoritas berpengetahuan baik sebanyak 7 responden $(20 \%)$

Penelitian ini sesuai dengan pendapat Notoatmodjo (2012) yang menyatakan bahwa pengetahuan merupakan faktor yang sangat penting dalam membentuk tindakan seseorang. Pengetahuan adalah hasil tahu yang telah terjadi setelah orang melakukan penginderaan terjadi melalui pancaindra manusia yakni indra penglihatan, pendengaran, penciuman, rasa, dan raba. Pengetahuan pada dasarnya terjadi dari sejumlah fakta dan teori yang memungkinkan seseorang untuk dapat memecahkan masalah yang dihadapinya, dimana pengetahuan tersebut diawali dari tahu, memehami, apliksi dan mampu menguraikan materi yang telah dipelajari.

Penelitian ini sesuai dengan pendapat Irawati (2013) dimana pengetahuan berpengaruh terhadap terjadinya postpartum blues. Dari 37 responden yang diteliti terdapat 16 orang $(72,7 \%)$ responden berpengetahuan kurang dengan nilai $\mathrm{p}=0,006$. Asuhan pada masa postpartum termasuk pemberian informasi memiliki hubungan yang bermakna untuk mencegah terjadinya postpartum blues

Berdasarkan hasil penelitian, bila dikaitkan dengan pengetahuan responden bahwa lebih banyak responden memiliki pengetahuan yang kurang tentang sindrom baby blues. Pengetahuan yang diharapkan adalah pengetahuan yang baik. Hal ini disebabkan kurangnya keingintahuan ibu postpartum tentang sindrom baby blues, kurangnya informasi pada responden sehingga dapat mempengaruhi ilmu pengetahuan responden yang masih rendah, umur responden yang terlalu muda untuk menikah sehingga kurangnya persiapan dalam menyambut kelahiran bayi baik secara fisik maupun mental serta tingkat pendidikan dan tidak memiliki pekerjaan yang membuat ibu postpartum sulit untuk mendapatkan informasi yang lebih khususnya tentang sindrom baby blues. 


\section{Syndrome baby blues}

Berdsarkan hasil penelitian dari 35 responden, mayoritas ibu post partum yang tidak mengalmi syndrome baby blues yaitu 19 orang $(54,3 \%)$ dan minoritas yang mengalami syndrome baby blues yaitu 16 orang $(45,7 \%)$.

Didukung oleh penelitian Roswiyani (2010) bahwa dari 4 orang subjek, 3 orang mengalami DPM dan 1 orang mengalami babyblues. Ragam gejala mereka tampilkan memiliki kemiripan satu sama lain, akantetapi pada satu subjek, kondisi tersebut hanya berlangsung daam waktu 1 minggu setelah melahirkan sedangkan pada ketiga orang lainnya gejala tersebut berlangsung dalam rentang waktu yang cukup lama yaitu 2 dan 3 bulan.

Ibu yang mengalami baby blues ini sering kali menangis secara terus menerus tanpa sebab yang pasti dan mengalami kecemasan. Keadaan ini berlangsung pada minggu pertama setelah melahirkan. Meskipun pengalaman ini tidak menyenangkan namun biasanya kondisi ini akan kembali normal setelah 2 minggu tanpa penanganan khusus. Jadi yang dibutuhka adalah menetramkan dan membantu ibu baru ini mengasuh bayi dan melakukan pekerjaan rumah.

\section{Hubungan Pengetahuan Ibu Post partum dengan Syndrome baby blues}

Berdasarkan tabel4 diatas, dari 7 orang responden yang pengetahuannya baik, mayoritas tidak mengalami syndrome baby blues yaitu 5 orang (71\%), dan minoritas mengalami syndrome baby blues yaitu 2 orang (29\%). Dari 11 orang responden yang berpengetahuan cukup, mayoritas yang mengalami syndrome baby blues yaitu 9 orang $(82 \%)$, dan minoritas tidak mengalami syndrome baby blues yaitu 2 orang (18\%). Dari 17 orang responden yang berpengetahuan kurang, mayoritas tidak mengalami syndrome baby blues yaitu 12 orang $(70 \%)$ dan minoritas mengalami syndrome baby blues yaitu 5 orang (30\%)

Hasil analisa menggunakan uji Chi-squaredengan $\alpha$ 0,05 dengan $\mathrm{df}=2$ dan $\mathrm{X}^{2}$ tabel adalah 5,991 dan ditetapkan $X^{2}$ hitung adalah 11,15.Dimana $X^{2}$ hitung lebih besar daripada $X^{2}$ tabel $(11,159>5,991)$,dengan p 0,004 $(\mathrm{p}<0,05)$, maka Ho ditolak dan Ha diterima, artinya terdapat hubungan yang signifikan antara pengetahuan dengan pemeriksaan pap smear

Penelitian ini sesuai dengan pendapat Notoadmodjo (2007) bahwa umur berkaitan erat dengan tingkatan pengetahuan dimana semakin tua umur semakin tinggi tingkat pengetahuan seseorang.Usia berkaitan erat dengan pengetahuan dimana semakin tua usia semakin banyak pula pengalaman yang didapat. Pengalaman adalah guru yang baik, yang maksudnya bahwa pengalaman itu merupakan suatu cara untuk memperoleh kebenaran pengetahuan.

Berdasarkan asumsi penulis bahwa ibu yang mengalami sindrom baby blues dipengaruhi beberapa hal seperti informasi yang diperoleh, pengalaman dalam kehamilan dan melahirkan sebelumnya dan juga adanya dukungan dari keluarga saat ibu mengalami post partum yang dapat membantu ibu dalam erawat dirinya dan juga bayi yang telah dilahirkan.
Berdasarkan hasil penelitian, pekerjaan juga dapat mempengaruhi pengetahuan ibu dalam menyerap berbagai informasi.Hal ini dikarenakan dalam lingkungan kerja, seorang ibu dapat bertukar informasi dengan rekan kerjanya sehingga selain dapat saling bertukar pengalaman, dapat juga memperluas wawasan yang menambah pengetahuan ibu.Sedangkan ibu yang bekerja sebagai ibu rumah tangga berpengetahuan kurang disebabkan karena pekerjaan ibu yang membuat ibu sulit memperoleh informasi.Ibu yang bekerja sebagai ibu rumah tangga memiliki lingkungan pergaulan yang kurang luas disebabkan karena kesibukan di dalam rumah sehingga informasi yang diperoleh ibu sangat terbatas.

Penelitian ini didukung oleh penelitian Irawati (2014), bahwa suami memegang peranan penting dan diharapkan suami menyadari bahwa istri sangat membutuhkannya pada saat saat tertentu dan suami diharapkan ada saat istri membutuhkannya.Dukungan itu tidak hanya berupa dukungan psikologis tapi dukungan fisiologis, penilaian, informasi dan finansial sangat dibutuhkan oleh istri.Jadi dukungan yang diberikan itu dikemas secara utuh sehingga istri merasa nyaman dan dapat persalinan dengan baik.Untuk itu dukungan suami sangat dibutuhkan oleh perempuan setelah mengalami persalinan.

Berdasarkan hasil penelitian, pengetahuan ibu postpartum tentang sindrom baby blues juga dipengaruhi oleh dukungan keluarga dimana keluarga selain memberikan dukungan berupa semangat dan pemberi kebutuhan secara material, tetapi dapat sebagai pemberi informasi yang baik. Baik yang didapatnya dari media cetak, atau pengalaman yang pernah didengar dari orang lain. Sehingga ibu postpartum lebih banyak mendapatkan informasi yang baik bagi dirinya.Dimana hal itu sangat dibutuhkan bagi ibu postpartum.

\section{KESIMPULAN}

Hasil uji Chi-square antara pengetahuan ibu post partum dengan syndrome baby bluesdiperoleh nilai $\mathrm{p}=$ $0,015,(\mathrm{P}<0,05)$ artinya terdapat hubungan yang signifikan antara pengetahuan ibu post partum dengan syndrome baby blues dimana semakin baik pengetahuan ibu tentang syndrome baby blues maka kemungkinan ibu tidak akan mengalami syndrome baby blues yang lebih lama.

\section{SARAN}

1. Diharapkan kepada pimpinan klinik agar petugas kesehatan khususnya di Klinik Romauli Kec. Medan Marelan memberikan penyuluhan maupun pendidikan kesehatan tentang sindrom baby blues pada ibu postpartum dan juga keluarga

2. Diharapkan kepada petugas agar dapat memberikan hubungan terapeutik dalam memberikan pelayanan pada ibu post partum 


\section{DAFTAR PUSTAKA}

Chomaria, Nurul. 2013. Panduan Super Lengkap Kehamilan Kelahiran \& Tumbuh Kembang Anak bagi Muslimah. Jakarta : Ahad Books

Fatimah, Siti. 2009. Hubungan Dukungan Suami Dengan Kejadian Postpartum Blues Pada Ibu Primipara Di Ruang Bugenvile RSUD Tugurejo Semarang.Artikel Riset Keperawatan. Universitas Diponegoro Semarang

Hasma.2011. Faktor Risiko Baby Blues Syndrome Di BPS Lusia Sandaden Kelurahan Sudiang Raya Kecamatan Biringkanaya Kota Makassar Propinsi Sulawesi Selatan Tahun 2011.Proposal Penelitian. Universitas Muslim Indonesia Makassar

Hutagaol, Esther. 2010. Efektivitas Intervensi Edukasi pada Depresi Postpartum.Tesis. Universitas Indonesia Depok

Irawati, D dan Yuliani F. 2013.Pengaruh Faktor Psikososial terhadap Terjadinya Post Partum Blues Pada Ibu Nifas (Studi di Ruang Nifas RSUD R.A Bosoeni Mojokerto). Jurnal Penelitian. Mojokerto

Irianti, I. dan Nina, H. 2010.Buku Ajar Psikologi untuk Mahasiswa Kebidanan.Jakarta : EGC

Machmudah.2010. Pengaruh Persalinan dengan Komplikasi Terhadap Kemungkinan Terjadinya Postpartum Blues di Kota Semarang.Tesis. Universitas Indonesia Depok

Machmudah, dkk.2012. Persalinan Komplikasi dan kemungkinan terjadinya Postpartum Blues.Seminar Hasil-Hasil Penelitian. Universitas Indonesia Depok

Mansur, Herawati. 2006. Psikologi Ibu dan Anak untuk Kebidanan.Jakarta : Salemba Medika

Marshall, Fiona. 2004. Mengatasi Depresi PascaMelahirkan. Jakarta : Arcan
Nolan, Mary. 2010. Kelas Bersalin. Yogyakarta : Golden Books

Notoatmodjo, Soekidjo. 2007. Kesehatan Masyarakat. Jakarta : Rineka Cipta

Politeknik Kesehatan Medan. 2012. Panduan Menyusun Karya Tulis Ilmiah. Medan

Ragil, Putri, dkk. 2013. Hubungan Dukungan Sosial Suami Dengan Gejala Gangguan Psikologi Postpartum Blues Selama Masa Nifas Pada Ibu Primipara Di Bidan Praktik Swasta Kecamatan Wagir Dan Kecamatan Sukun Kota Malang. Jurnal Penelitian. Malang

Rein, M. 2012. Baby Blues Tak Boleh Dianggap Enteng. Diakses 1 Februari 2014: http://sehat-ituhealthy.wordpress.com/2008/11/baby-blues-takboleh-dianggap enteng.html

Saleha, Sitti. 2009. Asuhan Kebidanan pada Masa Nifas.Jakarta : Salemba Medika

Suherni, dkk. 2009. Perawatan Masa Nifas. Yogyakarta : Fitramaya

Suparyanto, 2012.Konsep Paritas. Diakses 15 April 2014: http://www.carantrik.com/2012/02/konsepparitas.html

Yeyeh, A., dan Lia Y. 2011. Asuhan Kebidanan IV (Patologi Kebidanan). Jakarta: Trans Info Media

Zakirman, Devita. 2011. Hubungan Paritas dan Pendidikan dengan Pengetahuan Ibu Hamil tentang Hubungan Seksual Pada Kehamilan Trimester III di Rs. Kia Kota Bandung Bulan September 2011. Jurnal Penelitian. Bandung.

Zan, H., dan Namora L. 2011. Pengantar Psikologis untuk Kebidanan.Jakarta : Kencana Prenada Media Group. 